\title{
Theorizing Collective Green Actions: An Institutional Perspective for the UAE Industries
}

\author{
Wenshin Chen
}

Abu Dhabi University, Abu Dhabi, UAE

\begin{abstract}
The notion of "green" has gained increasing attention over the years. Many major companies have made significant attempt to better fit into the green concept. Are these corporate marketing endeavors purely based on their environmental consciousness or driven by their intention to gain social recognition which could in turn reshape their corporate image that better reflects the concerns of environments, climate change, and green IT issues? This question is interesting to explore because the complexity and difficulty of 'green endeavor' has been widely addressed among practitioners and researchers. Based on an institutional perspective, this paper thus proposes a theoretical framework that helps organizations analyze these green issues in the competitive marketplaces. Propositions of the framework theorize that organizations will inevitably face various isomorphic pressures that lead them to initiate or follow green actions collectively. Those isomorphic pressures usually stem from influential agencies or initiatives in their respective fields such as REACH (Registration, Evaluation, Authorisation and Restriction of Chemicals), the Green Grid, Health Insurance Portability and Accountability Act (HIPAA), and European Waste Catalogs (EWC). The implications of this theoretical framework suggest that organizations need to undertake green actions shiftily in order to continuously validate their competitive status in the global, networked economy. The cost of failing to do so, i.e. being 'not' green, might be beyond any organization's measure in the long term. Further implications of collective green actions are made to the UAE local industries and research community.
\end{abstract}

Keywords: green, isomorphism, corporate image, institutional pressure

\section{Introduction}

\section{Research Motivation}

There is no doubt that the notion of "green" has become one of the most concerning subjects in the global society and economy in recent years (Sturgeon, 2006). Research endeavor across various academic disciplines has widely examined related issues and their significant impacts (Jørgensen and Jørgensen, 2009; Parker, 2009; Smith, 2007). The corporate world, similarly, has witnessed growing attempts made by many major companies to declare social responsibilities by demonstrating their green initiatives. For example, Toyota has recently claimed in one of its environment driven campaigns "the best way for a car company to have impact on the environment is to have as little impact as possible." The advertisement emphasized how the company's automanufacturing materials can be recycled and eventually integrated into the environment. Chevron has also embarked on green initiatives in its recent 'human energy' commercials drawing viewers' attention to its endeavor on environmental issues and renewable energy solution instead of traditional oil and energy production. When one of those 
commercials concluded "imagine that an oil company has part of solution" it was clear that the company's intention was to reshape its corporate image to better fit into a global demand of green, renewable energy solution.

These corporate marketing strategies inspire an interesting question, i.e. what are the fundamental driving forces behind their collective green initiatives? Although these major corporations are situated in different industries and compete for diverse market segments and resources, they all undertake similar actions in the growing awareness of environmental issues worldwide. As such, one cannot help but inquire whether their actions are motivated by corporate social responsibility in general and their environmental consciousness in particular, or driven by their marketing strategy to reshape their corporate status that better fits into greener social images (Chen, 2007) and reflect the concerns of environments, climate change, and green IT issues? As practitioners increasingly address the complexity and difficulty of 'green endeavor' (Gillies, 2007; Kanellos, 2007), it will become interesting to further explore these questions raised. One of the typical examples illustrating such complexity is that green endeavor, as attractive as it might sound, often requires higher consumption or service prices. For instance, studies have shown that 'green economy' has elevated government debt in Spain and is likely to demand higher taxes in he U.S.A. (Ortega, 2009). Another example is the integration of alternative energy into modern architecture design. While the subject of alternative energy has attracted worldwide attention over the years, the actual cost of implementing alternative energy infrastructure, either solar, wind or other sources, remains substantially high. More specifically, in the U.S.A. market, it will require approximately $\$ 500$ billion of infrastructure investment just to generate $20 \%$ of electricity from wind (Kanellos, 2007 ) and $\$ 3$ to $\$ 10$ billion of investment is needed to allow $\$ 4$ billion portfolio of real estate properties to be 'green' (Gregor, 2010).
The high cost of being green becomes even more burdensome for governments and corporations when the global economy experiences rising uncertainty and difficulty. As of July 2011, both governments of Spain and U.S.A. faced critical financial issues. Therefore, meeting social responsibility for greener environment might not be the most critical element on each government's political or economy agenda. From consumers' standpoints, similar concerns arise. Although some consumers claimed that they were supportive of environmentally friendly features, their motives were mostly due to the belief that environmentally friendly or energy efficient products could lead to substantial cost saving in the long run (Anonymous, 2010). In other words, consumers' actions were largely, if not completely, driven by economic benefits rather than social or environmental concerns. When cost saving (i.e. economic benefits) could not justify investment on environmentally friendly products, car buyers or homeowners in the U.S. tended to maintain their existing choices (Opdyke, 2007). Therefore, if 'being green' has such a high price to pay, why would corporations care for green economy and how can they afford to invest in environmentally friendly infrastructure, particularly when the global economy required excessive stimulus support from the governments and many governments themselves face financial difficulty on their own (Gillham, 2009)?

The purpose of this paper is thus to discuss the price of being green and mostly to propose a theoretical framework that helps better understand the green actions of corporations. The central research questions inquire, "Does the high price of being green, as suggested by many practitioners, matter?" and "How do corporations worldwide and in the UAE industries particularly undertake green initiatives?" Drawing from the theoretical framework built upon social and institutional perspectives, propositions are made to suggest potential green actions of corporations in today's global economy. The knowledge contribution of this 
conceptual development is to raise awareness of social and political landscape in which corporations reside and compete and to encourage a more environmentally friendly business and IT practice that helps shape a more sustainable corporate image. The implications of this theoretical framework will be particularly relevant to the UAE (United Arab Emirates) industries because of its rapidly growing economy that has gained worldwide attention in recent years and its driving economy forces situated in the oil and gas industry that fundamentally concerns environmental issues in the long run.

\section{Theoretical Framework}

Drawing from institutional theory in general and isomorphism in particular, the theoretical foundation of this paper argues that organizations in competitive marketplaces will inevitably face institutional pressures that lead them to act on green initiatives collectively over time (DiMaggio and Powell, 1983; Lawrence, 1999; Slack and Hinings, 1994). According to institutional theorists, isomorphism is the notion that explains collective actions taken by a group of actors situated in the same institutional field (Lawrence, 1999; Oliver, 1991). While the organizations' collective actions might be moving toward a similar direction such as entering a new market or making a similar choice such as implementing the same technology, the rationale behind it is largely driven by tremendous pressures that they face in their competitive fields (DiMaggio and Powell, 1983). As such, these pressures are often considered as bandwagon effects (Abrahamson and Bartner, 1990; Tan, 2002).

More specifically, these bandwagon pressures could be understood through three major sources, which serve the theoretical framework on which this paper is built: coercive, mimetic and normative forces (Lawrence, 1999; Oliver, 1991). Coercive pressure is a dominant force that requires actors to comply with certain collective practice otherwise formal sanction or severe consequence will occur. At the individual or group level, coercive pressure is most likely to emerge when individual actors fear to be left behind (Abrahamson, 1991) or be excluded from a social group (Chen and Wong, 2003). At the organizational or industrial level, coercive pressures could stem from powerful sources such as governmental regulation or industrial legal actions (DiMaggio and Powell, 1983).

Mimetic pressure, in contrast, is mostly shaped by environmental and technological uncertainty (Slack and Hinings, 1994). As emerging technology rapidly develops, risks associated with technology uncertainty would be inevitable. While facing such uncertainty, actors in a social group would often fear to be different (Abrahamson, 1991) and in turn tend to model after those who have successfully legitimized themselves in the field (Chen, 2005; DiMaggio and Powell, 1983). Such modeling process is often advocated by opinion leaders that influence those who are inexperienced or less knowledgeable in innovation (Ginsberg and Abrahamson, 1991; Rogers, 1995) and could be considered as a form of interpersonal reproduction that witnesses emerging technology being widely diffused among users (Williams, 2004). At the organizational or institutional level, mimetic pressure often leads to certain benchmarking that allows organizations to measure themselves against those who have been successfully adopted certain technology or implemented new policies (Lawrence, 1999; Oliver, 1991).

Finally, normative pressure is largely derived from social norms (Dacin, 1997) and often caused by the exchange of information among group members (DiMaggio and Powell, 1983). Such information exchange inevitably creates comparison among group members (Greenwood, Suddaby and Hinings, 2002; Lounsbury, 2002) and in turn urges them to retain group identity and legitimacy by complying with social norms that are commonly expected in the group (Lawrence, 1999). As more members identify themselves with such collective practices, certain bandwagon effects are likely to emerge and further urge 
remaining members to act similarly (Staw and Epstein, 2000; Westphal, Gulati and Shortell, 1997). In other words, the more widely diffused an action, the higher the normative pressure (Abrahamson and Bartner, 1990).

\section{Propositions}

Based on this theoretical framework, three propositions are made in relation to the research questions.

Proposition one (P1): Increasing coercive pressures faced by organizations in the same field will lead to their collective green action.

Proposition two (P2): Increasing mimetic pressures faced by organizations in the same field will lead to their collective green action.
Proposition three (P3): Increasing normative pressures faced by organizations in the same field will lead to their collective green action.

In other words, these propositions implicitly suggest that the high price of being green does not matter in the institutional field because the increasing isomorphic pressures faced by the organization will ultimately shape their collective green action. Here, green action is defined in a broad sense that could include any activity or policy that is related to environmentalism or sustainability such as climate change, renewable energy, green computing, recyclability, waste management and so on. Detailed arguments are provided below.

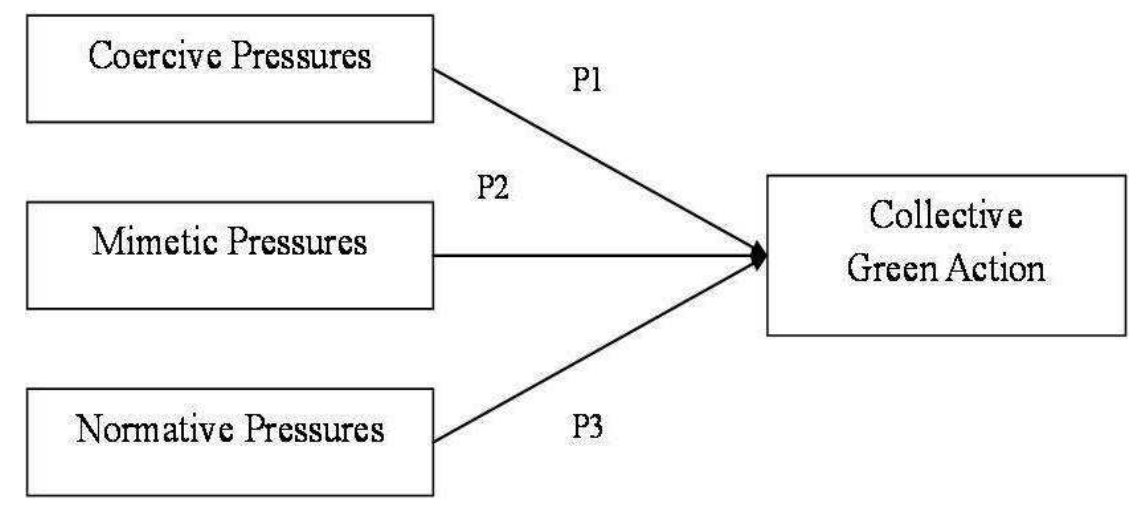

Figure 1. The Conceptual Model

For proposition one, coercive pressures that will force organizations to act on green initiatives will be increasingly emerging in their institutional fields because governmental regulation and/or professional sanction have progressively established standard for environmental movement and sustainability. REACH (Registration, Evaluation, Authorisation and Restriction of Chemicals), a recent EU (European Union) regulation that addresses the production and use of chemical substances and their potential impacts on health and environmental issues, establishes the strictest regulation on chemical substance and subsequently influences all industries in the world. Any company that is interested in trading with
EU will need to comply with the law. This governmental regulation is one example that reinforces coercive pressures on organizations in the institutional field so that their collective green action is initiated.

Professional sanction could also shape coercive pressures in the field that forces organizations which intend to compete in the same industry to comply with industrial standards and consequently lead to isomorphic action. ISO (International Organization for Standardization), for instance, creates many standards that addresses environment, health protection, and safety issues including environmental protection, wastes, water quality, air quality, and radiation protection. If an 
organization wishes to reach a competitive status that is internationally recognized, it will be inevitably questioned whether its production, operation, and/or management processes comply with ISO guidelines or obtain certain ISO status in the area of concern. Failing to do so might not result in formal penalty. It will, however, exclude the organization from the competitive field and thus impose coercive pressures on organizations to a degree that their collective green action is guaranteed.

For proposition two, organizations will face increasing mimetic pressures to act on green initiatives because benchmarking successful or leading companies or following widely recognized notions in the field is considered a less vulnerable strategy in an uncertain, complex environment. As the green related notion such as climate change, global warming, sustainability, green IT etc continues to cause global concern, organizations will inevitably feel the pressure to follow this trend. Such pressure will noticeably increase after some leading companies have adopted certain polices or undertaken certain green initiatives. For example, the Green Grid, a global IT consortium and one of the initiatives associated with the notion of green computing, was formed in 2007 by a group of IT companies and professionals to develop and promote energy efficiency for data centers and business computing ecosystems. According to their mission statement, action plans sought to achieve such objectives including: (1) defining meaningful, user-centric models and metrics, (2) promoting the adoption of energy efficient standards, processes, measurement methods and technologies, and (3) developing standards, measurement methods, processes and new technologies to improve performance against the defined metrics (www.thegreengrid.org).

As these objectives and action plans are clearly in line with the notion of green computing, they are likely to establish an international standard for the IT industry, particularly considering the influential power of its founding members in the IT industry; those founding members include
AMD (Advanced Micro Devices), Dell, HP, IBM, Intel, Microsoft, Silicon Graphics International Corp, Sun Microsystems, Schneider Electric, and VMware. Moreover, the Green Grid has established collaborative relationships with various institutions to further advance its influence. These collaborations include standard bodies (e.g. The American Society of Heating, Refrigerating and AirConditioning Engineers, The Distributed Management Task Force, Inc., and The Storage Networking Industry Association), governmental agencies (e.g. US Department of Energy, and US Environmental Protection Agency), and other institutions such as Green IT Promotion Council and IT Industry Council. In other words, hundreds of companies and thousands of participant members are a part of the Green Grid network. To be better recognized in the field, IT related companies will most likely to face mimetic pressures to adopt standards, policies, regulations, or suggested practices by the Green Grid and its collaborators. As its network continues to grow, it is not difficult to foresee its influences in the IT industry and subsequently greater institutional pressures imposed on organizations in the field to adopt more energy efficient practice.

For proposition three, normative pressure will increasingly urge organizations in the same field to act on similar green initiatives because the notion of green is increasingly establishing itself as a norm in the industry so that common practices of green activities are expected in the same field. In the healthcare industry, for instance, the widespread use of electronic data interchange (EDI) in the US has become an emerging norm since the enactment of Health Insurance Portability and Accountability Act (HIPAA). Many hospitals have recently implemented or in the process of considering implementing electronic medical record (EMR) systems to improve data accuracy and transaction efficiency. While the initiative of HIPAA seeks to reduce medical fraud or malpractice, the electronic based records as opposed to traditional paper based records tremendously reduce paper waste 
and storage capacity; both are significant parts of green action in organizations. As the trend continues, more healthcare organizations will seek ways to improve their green activities, which in this case reduce substantial cost as well, and in turn collectively shape greater normative pressures on those who have not yet done so.

Similar green actions could be found in the notion of eco-friendly dentistry through which the dentistry industry seeks sustainable ways to reduce environmental impacts. A 4-R's strategy guides the industry's green action. It includes (1) rethink-to develop a new mindset for green action, (2) reduce-to decrease consumption of the Earth's resources, (3) reuse-to prolong the use of medical items, and (4) recycle-to avoid medical waste and transform it into a new product. Dental professionals situated in the field will face considerable pressure not to follow such imperative trend. Another example is common practice of medical waste management in the healthcare industry. In the US, such practice has been established since the late 1980s through Medical Waste Tracking Act. In Europe, European Waste Catalogs (EWC) also provides a list of specific codes to guide waste management in the industry. No healthcare organization situated in the field could avoid these common practices since they have been widely sanctioned. Increasing normative pressures will thus continue to shape organization's collective green action.

\section{Discussion}

In the current economy, the price of being green is perhaps substantially higher (e.g., the price of a hybrid sedan is still approximately 50 percent higher than a regular sedan). However, increasing pressures emerging in the industry will force, urge, or lead organizations (and likely individuals) to collectively adopt green action. The rationale behind it is largely driven by institutional perspectives instead of economic ones. As argued earlier, organizations situated in the same field will collectively face similar pressures from governmental agencies, environmental uncertainty, and institutional norms.

When these pressures are created by governmental agencies or professional associations (i.e. coercive pressures), organizations in the field cannot afford not to comply with the regulation or policy otherwise severe penalty may occur. When the pressures are driven by leading institutions (e.g. the Green Grid), a more secure strategy for an organization to survive in the field is to benchmark those leading institutions or associations. When the pressures are shaped by the industrial norm that has been commonly sanctioned and practiced in the field, it is simply difficult for an organization not to follow such norms. These pressures (coercive, mimetic, and normative) will thus increasingly shape organizations' collective actions in the field whether the price of being green is high or not.

Since the notion of green is broad and can be applicable to all industries, it is reasonable to state that no organization can avoid the green trend in the long run if it intends to compete and survive in its respective field. While the price of being green might be higher in the contemporary economy, institutional pressures faced by organizations in the field will be even too high in the long run for them to avoid green actions. Moreover, intangible benefits of being green (or cost of not being green) might be beyond any scale that an organization could measure. The most obvious case recently was the Deepwater Horizon oil spill (i.e. BP oil spill), the largest offshore oil spill in the US history that caused disastrous environmental impacts on the Gulf of Mexico and beyond. This disaster inevitably created a stigma on the BP's green image. Consequently, its stock price dropped substantially from $\$ 60.09$ on April 21 (when the disaster began) to $\$ 27.20$ on June 25, 2010 (when the paper was written), a total value loss of $\$ 105$ billion, not including over $\$ 3$ billion of cleaning expenditures accrued and other liability resulted from the incident. 
In reflection, perhaps the price of being green is substantially higher on the surface. In the long run, organizations will face increasing pressures in the field to comply with the green action that is commonly recognized and sanctioned in the contemporary society and industry. In other words, the matter is no longer about the price of being green but about the green image that will help an organization to survive better and compete longer in the field. When an organization catches a green stigma as BP did, it could immediately lose its competitiveness and perhaps long term survival. For proactive organizations, enacting green actions and acquiring green images sooner might be a smarter strategy to help them compete better ultimately.

\section{Implications for the UAE Industries}

The implications for organizations situated in the UAE are at least twofold. First, for leading organizations, the emerging markets in the UAE setting provide enormous potentials for initiating green actions that could lead the industrial standard and strengthen an organization's green image and competitive status. The reason is that green initiatives only begin to gain the industrial recognition in the UAE. Most organizations have not yet integrated green initiatives into their business processes or operational routines. Environmental awareness could still be much further developed in the local industries. If a leading organization establishes a well-defined green strategy and integrates it into business operations, it could create enormous pressures on other organizations in the field. For example, in the oil and gas industry, ADNOC (Abu Dhabi National Oil Company), one of the world's largest oil companies by oil reserve, can be a green benchmark for other companies connected to the industry in the UAE or in the MENA (Middle East and North Africa) region. The benefit for ADNOC to shape its corporate green image will be similar to recent green strategies marketed by Chevron as introduced in the beginning of the paper. A more profound long term effect is that a greener corporate image can help ADNOC expand its business horizons and venture into other industries as oil and gas reserve will eventually expire.

Similarly, a famous local example that has gained an increasing attention worldwide is Masdar City. Created in 2006, Masdar is a planned city that seeks to completely rely on solar and renewable energy and in turn build a sustainable environment that achieves zero carbon, zero waste objectives. Situated in Abu Dhabi city, Masdar, due to its increasing global recognition and endorsement, will soon host the headquarter of International Renewable Energy Agency (IRENA). Designed to cover 6 square kilometers, Masdar is intended to house 45,000 to 50,000 residents and 1500 businesses that specialize in environmentally friendly products and services. Despite such high number of commuting individuals, Masdar does not allow automobiles within the city. All commuting will depend on public or personal transit systems. The first phase of the project is expected to complete in 2015 while the final phase will be achieved in another 5 to 10 years. Upon completion, Masdar City will host the largest hydrogen power plant in the world, along with much other alternative energy. Despite its high investment cost, Masdar is supported by Abu Dhabi Government and is predicted to be an iconic establishment in the UAE. As such, Masdar could increase institutional pressures on local organizations that have or intend to establish business partnerships with it. In the long run, these institutional pressures, most likely normative and mimetic ones, will urge, if not force these local organizations to act on their green initiatives accordingly.

The second implication for the local industry in the UAE is that smaller or less influential organizations in the local industry might need to pay close attention to the emerging developments of green initiatives advocated by leading organizations or governmental agencies. These rapidly growing developments might soon create new green-related policies that regulate how business operations are governed in the UAE industries so that more environmentally sensitive business 
systems could be maintained in the country. The example of ADNOC aforementioned signifies that all of its upstream and downstream subsidiaries and suppliers will need to incorporate green initiatives accordingly in order to continue partnering with ADNOC. Even if the original investment for green operations might be rather costly for smaller organizations, it will be more strategically sensible to undertake these green initiatives sooner than later so that a greener corporate image is well established. When smaller organizations fail to do so, it will become more difficult for them to gain societal recognition; as smaller organizations generally lack financial or other sources that are needed to reverse a poor corporate image (if it occurs), their long turn survival in their respective sectors might thus be questionable.

\section{Concluding Remarks}

To sum, the conceptual model presented in this paper encourages organizations to evaluate green issues in their respective industries from, not just intraorganizational, but mostly interorganizational perspectives. In doing so, organizations can realize greater institutional forces, notably coercive, mimetic, and normative pressures, in their competitive environment that shape emerging green initiatives and policies. These new green initiatives might be opportunities for leading organizations such as ADNOC and Masdar to create institutional pressures on other organizations in the field. They could also be challenges that determine smaller organizations' long turn survival. Even though the investment on green initiatives could be costly, institutional pressures created by leading organizations, governmental agencies, and/or global demand will inevitably lead to the industry's collective green action. As such, organizations might consider undertaking green actions sooner than later so that their corporate image could be better maintained, if not enhanced. Due to the emerging nature of subject matters in general and its implications in the UAE industries in particular, empirical examinations of the theoretical framework proposed in this paper could provide fruitful research venues that help enhance the existing body of knowledge in relation to green concepts, environmentalism, and/or sustainability.

\section{Acknowledgement}

This research project was sponsored by the Industry Connectivity Research Grant of Abu Dhabi University.

\section{References}

Abrahamson, E. (1991). "Managerial Fads and Fashions: The Diffusion and Rejection of Innovations," Academy of Management Review, 16 (3), 586-612.

Abrahamson, E. \& Bartner, L.R. (1990). 'When Do Bandwagon Diffusions Roll? How Far Do They Go? and When Do They Roll Backwards?: A Computer Simulation,' Academy of Management Proceedings, San Francisco, CA.

Anonymous "British Columbians See Value in Being Green: Majority Would Pay More for an Environmentally Friendly Home," [Online], [Retrieved April 14, 2010].

Chen, W. (2005). "Isomorphism and MCommerce Strategy," The Fifth International Conference on Electronic Business (ICEB), December, Hong Kong.

Chen, W. S. \& Wong, S. F. (2003). "An Empirical Examination of the Use of Mobile Technology - A Social Pressure Perspective," The Third International Conference on Electronic Business (ICEB), December, Singapore.

Dacin, M. T. (1997). "Isomorphism in Context: The Power and Prescription of Institutional Norms," Academy of Management Journal, 40 (1), 46-81.

DiMaggio, P. J. \& Powell, W. W. (1983). "The Iron Cage Revisited: Institutional Isomorphism and Collective Rationality in Organizational Fields," American Sociological Review, 48 (2), 147-163.

Gillham, C.(2010). 'The Price of Being Green: Can We Still Afford to Invest in an 
Environmentally Friendly Economy?,' [Online], [Retrieved April 14, 2010]. www.newsweek.com.

Gillies, A.T. (2010). 'It's not Easy Being Green,' [Online], [Retrieved April 14, 2010]. www.forbes.com.

Ginsberg, A. \& Abrahamson, E. (1991). "Champions of Change and Strategic Shifts: The Role of Internal and External Change Advocates," Journal of Management Studies, 28 (2), 173-190.

Greenwood, R., Hinings, C. R. \& Suddaby, R. (2002). "Theorizing change: The Role of Professional Associations in the Transformation of Institutionalized Fields," Academy of Management Journal, 15 58-80.

Gregor, A. "Seeing the Investor Value in Being Green," [Online], [Retrieved April 14, 2010]. www.nytimes.com.

Jørgensen, M. S. \& Jørgensen, U. (2009). "Green Technology Foresight of High Technology: A Social Shaping of Technology Approach to the Analysis of Hopes and Hypes," Technology Analysis \& Strategic Management, 21 (3), 363-379.

Kanellos, M. "Why it's not Easy Being Green," [Online], [Retrieved April 14, 2010]. news.cnet.com.

Lawrence, T. B. (1999). "Institutional Strategy," Journal of Management, 25 (2), 161-188.

Lounsbury, M. (2002). "Institutional Transformation and Status Mobility: The Professionalization of the Field of Finance," Academy of Management Journal, 45 (1), 255-266.

Oliver, C. (1991). "Strategic Responses to Institutional Processes," Academy of Management Review, 16 (1), 145-179.

Opdyke, J. "The (too high) Price of Being Green Deters Homeowners," [Online], [Retrieved April 14, 2010]. http://www.realestatejournal.com/homeg arden/20070521-opdyke.html.
Ortega, I. "The High Cost of Being Green," [Online], [Retrieved April 14, 2010]. http://www.heritage.org.

Parker, R. (2009). "From Blue Skies to Green Skies: Engine Technology to Reduce the Climate-Change Impacts of Aviation," Technology Analysis \& Strategic Management, 21 (1), 61-78.

Rogers, E.M. (1995). 'Diffusion of Innovation,' The Free Press New York, NY.

Slack, T. \& Hinings, B. (1994). "Institutional Pressures and Isomorphic Change: An Empirical Test," Organization Studies, 15 (6), 803-827.

Smith, A. (2007). "Translating Sustainabilities between Green Niches and Socio-Technical Regimes,"Technology Analysis \& Strategic Management, 19 (4), 427-450.

Staw, B. M. \& Epstein, L.D. (2000). "What Bandwagons, Bring: Effects of Popular Management Techniques on Corporate Performance, Reputation, and CEO Pay," Administrative Science Quarterly, 45 523556.

Sturgeon, W. "Being "green": Practical, Possible... and Profitable?," [Online], [Retrieved April 14, 2010]. www.silicon.com.

Tan, Z. (2002). "Testing Theory of Bandwagons--Global Standardization Competition in Mobile Communications," International Journal of Information Technology \& Decision Making, 1 (4), 605619.

Westphal, J. D., Gualti, R. \& Shortell, S. M. (1997). "Customization or Conformity? An Institutional and Network Perspective on the Content and Consequences of TQM Adoption," Administrative Science Quarterly, 42 (2), 366-394.

Williams, R. (2004). "Management Fashions and Fads: Understanding the Role of Consultants and Managers in the Evolution of Ideas," Management Decision, 42 (6), 769-780. 